\title{
Tax Competition with Heterogeneous Firms
}

\author{
John Burbidge \\ University of Waterloo \\ Katherine Cuff \\ McMaster University \\ John Leach* \\ McMaster University
}

\begin{abstract}
A model of tax competition in which firms earn rents is described. The size of these rents, coupled with the degree to which the firms are foreign-owned, determine the equilibrium tax rates. The existence of rents significantly alters some generally accepted results involving the possibility of a Pareto-improving common tax rate and the underprovision of publicly provided goods.
\end{abstract}

*We are grateful to Robin Boadway, James Brox, Lutz-Alexander Busch, Clemens Fuest and Luca Micheletto for their helpful comments. We also thank seminar participants at the 2003 CEA Meetings, the University of Waterloo Economics Department, the NBER/CESifo TAPES Conference on Fiscal Federalism, and the 60th Congress of the IIPF, and the Social Science and Humanities Research Council of Canada for financial support. 


\section{Introduction}

The ability of firms to move to other tax jurisdictions places governments in a quandary. The governments want the revenue that can be earned by taxing profits, but they are aware that higher taxes will induce some firms to relocate. An extensive literature has examined the behaviour of competing governments under these circumstances. A standard assumption of this literature is that capital is homogeneous. This paper begins with an alternative assumption, that the capital is embodied in firms and that the firms are intrinsically different. ${ }^{1}$ Specifically, each firm's productivity varies across regions, and productivity in a particular region varies across firms. Almost all firms earn rents in equilibrium. ${ }^{2}$ The implications of this assumption are investigated under two different tax regimes. The first regime is the one used by Hamada (1966) and subsequently employed by a number of others, including Burbidge, DePater, Myers and Sengupta (1997) and Peralta and van Ypersele (2002). The governments are able to impose both a tax on profits and a lump-sum tax on incomes. Under this regime the governments have two instruments that can be used to meet two objectives: maximizing the economy's resources and allocating these resources between private and publicly provided goods. The second tax regime, found in Wilson's survey (1999), eliminates the lump-sum tax, so that the governments must compromise between competing ends when they choose their tax rates.

Under both tax systems the profits tax is higher in the presence of heterogeneity. Moreover, the tax rate increases with the extent of foreign ownership, and with a measure (described below) of the degree of heterogeneity. Although the governments choose to tax all rentsthat is what their tax instrument allows them to do - they would prefer to tax the rents that accrue to foreigners. An increase in either foreign ownership or firm heterogeneity increases the rents owed to foreigners, inducing the governments to set higher tax rates. Shrinking the degree of firm heterogeneity to zero causes the tax rate to converge to that predicted by the model with homogeneous capital.

These results resemble those obtained in models with mobile homogeneous capital when there is a cross-ownership of the immobile factor

\footnotetext{
${ }^{1}$ Each firm can be imagined to embody one unit of capital, as in Boadway, Cuff and Marceau (2004). Their model assumes that the firms are equally productive in all regions but subject to a regional production externality, whereas the current model emphasizes the differences among firms.

${ }^{2}$ Mansoorian and Myers (1992) consider the problem of rents from a different perspective. They assume that labour is the mobile factor and that workers have different preferences over regions. Here, almost all of the workers earn locational rents.
} 
(generally land). In these models, the fixed factor earns rents. Any tax on the mobile factor will be capitalized into the return to the fixed factor. The optimal capital tax will be zero if these land rents can be fully taxed (Huizinga and Nielsen, 1997). If the rents cannot be fully taxed, then foreign ownership of the immobile factor gives governments an incentive to use positive capital tax rates to raise revenue since part of the tax burden falls on nonresidents (Lee, 2003). The greater the degree of foreign ownership, the greater the 'tax-exporting incentive' and the higher the equilibrium capital tax rates. Capital tax policy is affected jointly by the amount of rents and the extent to which these rents accrue to nonresidents. This continues to hold when there is cross-ownership of a heterogeneous mobile factor.

A peculiarity of models with homogeneous capital is that, under the Hamada tax system (with returns to the fixed factor completely taxed), there are only two kinds of equilibria: ones in which every government sets its profits tax at zero, and ones in which there is a mixture of positive and negative rates. Both outcomes are inconsistent with casual observation: governments do seem quite prepared to tax profits. ${ }^{3}$ As well, the nature of these equilibria has a decisive impact on a related issue, the possibility that the adoption of a common tax rate would be Pareto improving. The current view is that a common tax rate would be Pareto improving - but only if the common rate were zero. ${ }^{4}$ Governments might think profits to be a tempting source of revenue, but they would all be better off if they became abstainers. Both of these results are undone by the introduction of heterogeneity. Every tax rate in a symmetric equilibrium is positive, and every tax rate in an equilibrium in which the regions are sufficiently similar is also positive. Furthermore, there is a range of Pareto-improving tax rates, and since this range is bounded by the equilibrium tax rates, it is quite possible that every Pareto-improving tax rate is positive.

Tax competition under the Wilson tax system generally leads to underprovision of publicly provided goods. Governments would provide the optimal quantity of a publicly provided good if firms were immobile;

\footnotetext{
${ }^{3}$ See Devereux, Griffith and Klemm (2002) for a review of the use of corporate taxes in the OECD.

${ }^{4}$ It seems to be common knowledge that, starting from the Nash equilibrium, both regions in a two-region world would benefit if they set their tax rates at zero. Peralta and van Ypersele (2002) attempt to extend this result to an economy with $n$ regions. They consider a policy of setting upper and lower bounds on the tax rates, and show that contracting these bounds can be Pareto-improving. They are unable to show that a common tax rate (i.e, eliminating the gap between the bounds) is Paretoimproving; but the details of their proof show that if this policy is Pareto-improving, the common tax rate can only be zero.
} 
but the mobility of firms constitutes a disincentive to setting high tax rates, causing governments to set lower tax rates and provide smaller quantities of the publicly provided good. However, both underprovision and overprovision become possible when the firms are heterogeneous. The governments view the rents accruing to foreigners as "free money" and are tempted to appropriate it through profits taxes. There are circumstances under which they will set tax rates so high that the publicly provided good is overprovided.

Section 2 describes the equilibrium attained by the economy under fixed tax rates. The governments anticipate the equilibrium that will be reached when they set their tax rates. Each government, taking the other government's tax policy as given, chooses the tax policy that makes its own region as well off as possible. The equilibrium tax policies are a Nash equilibrium: neither government can make its own region better off by unilaterally altering its own tax policy. Sections 3 and 4 describe these policies under the Hamada and Wilson tax systems respectively. Section 5 briefly concludes. All proofs are contained in the appendix.

\section{Competitive Equilibrium with Fixed Tax Rates}

The economy consists of two regions, denoted $A$ and $B$. There are $H_{i}$ workers in region $i$ (where $i$ is either $A$ or $B$ ). The workers are immobile, and each worker supplies one unit of labour at every wage rate. The governments of the two regions levy taxes, using the revenues to provide a private good to the workers within their regions. In this section the tax rates are taken to be exogenous.

The total number of firms is fixed, and each firm chooses to locate in one of the two regions. Each firm knows its own productivity, the tax rates, and the market-clearing wage in each of the two regions. It chooses its location and its employment of labour to maximize its aftertax profits.

The productivity of a given firm in the two regions is determined in part by its productivity factors $\left(\theta_{A}, \theta_{B}\right)$. The distribution of productivity factors across firms is described by the density function $g\left(\theta_{A}, \theta_{B}\right)$. Let $S$ be the set of pairs $\left(\theta_{A}, \theta_{B}\right)$ for which $g\left(\theta_{A}, \theta_{B}\right)$ is positive. It is assumed that there exist positive numbers $\underline{\theta}$ and $\bar{\theta}$ such that $S$ is bounded below by $(\underline{\theta}, \underline{\theta})$ and bounded above by $(\bar{\theta}, \bar{\theta})$. As well, it is assumed that there is a positive measure of firms for which $\theta_{A}$ and $\theta_{B}$ are not equal.

Let $y_{i}$ be a firm's output in region $i$, and let $h$ be the quantity of labour employed by the firm. Each firm's production function is

$$
y_{i}=(1 / \beta) \theta_{i}{ }^{1-\beta} h^{\beta}, 0<\beta<1 .
$$

The Cobb-Douglas function is used for tractability and incorporates two 
basic assumptions: the firm's output rises with its own productivity factor, and employment has a positive but diminishing marginal product.

A firm that has decided to locate in region $i$ can hire any quantity of labour at the market wage $w_{i}$. It will choose the quantity of labour $h$ that maximizes its profits $\pi_{i}$, where

$$
\pi_{i}=(1 / \beta) \theta_{i}{ }^{1-\beta} h^{\beta}-w_{i} h
$$

The profit-maximizing quantity of labour is

$$
\mathbb{Q}\left(\theta_{i}, w_{i}\right) \equiv \theta_{i}\left(w_{i}\right)^{-\frac{1}{1-\beta}}
$$

Evaluating the firm's output and profits at this employment level gives

$$
\begin{gathered}
y_{i}=(1 / \beta) \theta_{i}\left(w_{i}\right)^{-\frac{\beta}{1-\beta}} \\
\pi_{i}=(1-\beta) y_{i} .
\end{gathered}
$$

Let $t_{i}$ be the rate at which profits are taxed in region $i$. A firm chooses to locate in region $A$ if and only if

$$
\left(1-t_{A}\right) \pi_{A} \geq\left(1-t_{B}\right) \pi_{B}
$$

or equivalently,

$$
\left(1-t_{A}\right) y_{A} \geq\left(1-t_{B}\right) y_{B}
$$

Then, by (2), the firm locates in region $A$ if $\theta_{A} / \theta_{B}$ is greater than or equal to the critical value $k$, where:

$$
k=\frac{\mu_{1-t_{B}}}{1-t_{A}}{\frac{w_{A}}{w_{B}}}^{\text {१ } \frac{\beta}{1-\beta}}
$$

and it will locate in region $B$ otherwise.

The total demand for labour in each region is the integral of the labour demands of the firms that choose to locate in that region:

$$
\begin{aligned}
& H_{A}^{D}=\underbrace{\mathbf{Z}_{\bar{\theta}} \mathbf{Z}_{\bar{\theta}}}_{\underline{\theta}} \mathfrak{R} \theta_{B}\left(\theta_{A}, w_{A}\right) g\left(\theta_{A}, \theta_{B}\right) d \theta_{A} d \theta_{B} \\
& H_{B}^{D}=\underbrace{\mathbf{Z}_{\bar{\theta}} \mathbf{Z}_{k \theta_{B}}}_{\underline{\theta}} \boldsymbol{R}\left(\theta_{B}, w_{B}\right) g\left(\theta_{A}, \theta_{B}\right) d \theta_{A} d \theta_{B} .
\end{aligned}
$$

By (1), the regional labour demands can be written as

$$
H_{i}^{D}=\left(w_{i}\right)^{-\frac{1}{1-\beta}} z_{i}(k)
$$


where $z_{i}(k)$ aggregates the productivity factors of the firms that locate in region $i$ under a particular value of $k$ :

$$
\begin{aligned}
& z_{A}(k) \equiv \mathbf{Z}_{\bar{\theta}} \mathbf{Z}_{\bar{\theta}} \\
& z_{B} \quad \theta_{A} g\left(\theta_{A}, \theta_{B}\right) d \theta_{A} d \theta_{B} \\
& z_{\bar{\theta}} \mathbf{Z}_{k \theta_{B}} \theta_{\underline{\theta}} \quad \underline{\theta} \quad \theta_{B} g\left(\theta_{A}, \theta_{B}\right) d \theta_{A} d \theta_{B}
\end{aligned}
$$

Note that

$$
z_{A}^{\prime}(k)=-k z_{B}^{\prime}(k) \leq 0 .
$$

If an increase in the critical value $k$ causes some firms that had previously located in $A$ to shift to $B, z_{A}$ falls and $z_{B}$ rises. Each of the firms that switches from one region to the other is a marginal firm at the time of the switch, implying that $\theta_{A}$ is just equal to $k \theta_{B}$. The loss in region $A$ 's aggregate productivity is therefore $k$ times as large as region $B$ 's gain. ${ }^{5}$

The market-clearing wage in region $i$ equates the demand for labour, $H_{i}^{D}$, to the supply of labour, $H_{i}$. The market-clearing wage rate is

$$
w_{i}=H_{i}^{\beta-1} z_{i}(k)^{1-\beta} \quad i=A, B
$$

The total output of region $i$, denoted $Y_{i}$, is the integral of the outputs of the firms that choose to locate in that region. Using (2) and (6),

$$
Y_{i}={ }^{\mu} \frac{1}{\beta} \quad H_{i}^{\beta} z_{i}(k)^{1-\beta} \quad i=A, B
$$

For any given set of tax rates, equations (6) and (7) determine each region's wage rate and output in terms of $k$. To determine $k$ itself, substitute (6) into (4) to obtain

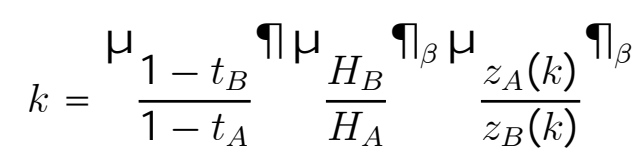

Equivalently,

$$
k=T L \mu(k)
$$

where

$$
T \equiv \frac{1-t_{B}}{1-t_{A}}, \quad L \equiv{\frac{H_{B}}{H_{A}}}^{\mathbf{q}_{\beta}}, \quad \mu(k) \equiv{\frac{z_{A}(k)}{z_{B}(k)}}^{\mathbf{q}_{\beta}}
$$

\footnotetext{
${ }^{5}$ The inequality in (5) is weak because $z_{i}^{\prime}(k)$ is equal to zero at any $k$ for which there are no pairs $\left(\theta_{A}, \theta_{B}\right)$ in $S$ such that $\theta_{A}$ is equal to $k \theta_{B}$, so that a small change in $k$ does not induce any firm to switch regions.
} 
The function $\mu(k)$ is non-increasing (specifically, it is negatively sloped if $z_{i}^{\prime}$ and $z_{B}^{\prime}$ are non-zero, and flat if they are equal to zero). The equilibrium value of $k$ is the unique solution to (8).

The tax rates and labour endowments determine $k$, and these parameters together with $k$ determine every firm's location and employment of labour, the market-clearing wage rates, and regional outputs. All of these variables are independent of the ownership structure of the firms.

An efficient allocation of firms maximizes the economy's total output. By (7), total output $Y_{A}+Y_{B}$ is a function of $k$. Differentiating total output with respect to $k$ and simplifying the resulting expression yields:

$$
\operatorname{sign} \frac{d\left(Y_{A}+Y_{B}\right)^{\lrcorner}}{d k}=\operatorname{sign}[L \mu(k)-k] .
$$

The properties of $\mu(k)$ imply that any stationary point of $Y_{A}+Y_{B}$ is a maximum. Equation (8) implies that the competitive equilibrium can only be efficient if profits are taxed at the same rate in each region $(T=1)$.

\section{Tax Competition under the Hamada Tax System}

Assume that the welfare of a worker in region $i$ is represented by a wellbehaved utility function

$$
U_{i}=u_{i}\left(c_{i} g_{i}\right)
$$

where $c_{i}$ is the worker's consumption of a private good, and $g_{i}$ is the worker's consumption of a publicly provided (but private) good. Assume also that one unit of the private good can be transformed into one unit of the publicly provided good. Each government's objective is to maximize the welfare of the representative worker in its region. Its only instruments are the tax rates that it controls. Two possibilities are considered.

1. Under the Hamada tax system, the government is able to impose taxes on profits and personal income. Since the workers are immobile, the tax on personal income is a lump-sum tax.

2. Under the Wilson tax system, the government is able to tax only profits. This restriction implies that each government's revenue from the profits tax must be exactly equal to its expenditure on the publicly provided good.

This section assumes that the Hamada tax system is in place, and the next section employs the Wilson tax system. 
Under either tax system, the governments correctly anticipate the competitive equilibrium associated with any vector of tax rates. A Nash equilibrium in the tax competition game consists of a set of taxes, one for each region, such that neither government can raise the utility of its representative worker by unilaterally altering its own tax rates.

Under the Hamada tax system, the existence of the lump-sum tax allows the government to separate the provision of the publicly provided good from the setting of the profit tax. The government of region $i$ faces the resource constraint

$$
c_{i}+g_{i}=\frac{R_{i}}{H_{i}}
$$

where $R_{i}$ are the total resources available to region $i$ - that is, it is the sum of all of the output that accrues to the government and to the workers of that region. For any value of $R_{i}$, the government will set the lump-sum tax to maximize $U_{i}$ subject to this constraint. Under this setting of the lump-sum tax rate, utility is an increasing function of $R_{i}$, and the role of the profits tax is simply to maximize $R_{i}$. Consequently, a Nash equilibrium under the Hamada tax system can be described more simply: it is a pair of tax rates $\left(t_{A}, t_{B}\right)$ such that neither government can increase its own resources by unilaterally altering its own tax rate.

The resources available to region $A$ are equal to that region's output, less the part of region $A$ 's after-tax profits that accrues to the residents of region $B$, plus the share of region $B$ 's after-tax profits that accrues to the residents of region $i$. The resources available to region $B$ are defined analogously. That is,

$$
\begin{aligned}
& R_{A}=Y_{A}-I \\
& R_{B}=Y_{B}+I
\end{aligned}
$$

where $I$ is the net transfer of profits from region $A$ to region $B$. This transfer arises because the residents of each region own shares of the firms that locate in the other region: $I$ is positive when region $B$ 's claim on the after-tax profits of the firms in region $A$ is greater than region $A$ 's claim on the after-tax profits of the firms in region $B$.

The magnitude of the net transfer of profits depends upon the way in which the ownership of the firms is split between the two regions. A quite general ownership structure is adopted here. Specifically, it is assumed that the share of a firm with productivity factors $\left(\theta_{A}, \theta_{B}\right)$ that is owned by the residents of region $i(i=A, B)$ is given by a differentiable function $s_{i}\left(\theta_{A} / \theta_{B}\right)$. The functions $s_{A}$ and $s_{B}$ have these properties at every admissible $q$ :

$$
\begin{gathered}
s_{A}(q)+s_{B}(q)=1 \\
s_{A}^{\prime}(q) \geq 0
\end{gathered}
$$


The first property states that every firm is completely owned by the residents of the two regions. The second property is a home ownership bias assumption. ${ }^{6}$ The ownership shares of any firm depend only upon the ratio of its productivity factors; and for any two firms, the residents of region $A$ own at least as much of a firm that is relatively more productive in their region than they own of a firm that is relatively less productive. These functions permit a range of ownership structures, with the following being the extreme cases.

1. Under constant ownership shares, $s_{A}(q)$ is equal to some constant $\bar{s}_{A}$ for all $q$.

2. Under exclusive home ownership, $s_{A}(q)$ is equal to 0 for all $q$ less than 1 , and equal to 1 for all $q$ greater than 1 . This ownership structure is not allowed because $s_{A}$ is assumed to be differentiable, but it can be approached arbitrarily closely.

Let $\sigma_{i j}$ be the integral of the productivity factors of the firms in region $i$, weighted by the shares of the firm owned by the residents of region $j$ :

$$
\begin{aligned}
& \mathbf{Z}_{\bar{\theta}} \mathbf{Z}_{\bar{\theta}}
\end{aligned}
$$

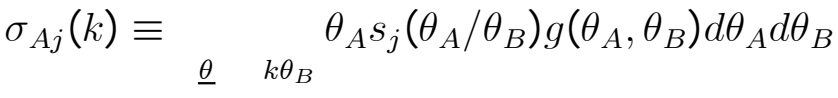

$$
\begin{aligned}
& \mathbf{Z}_{\bar{\theta}} \mathbf{Z}_{k \theta_{B}} \\
& \sigma_{B j}(k) \equiv{\underset{\underline{\theta}}{\underline{\theta}}}_{\underline{\theta}} \theta_{B} s_{j}\left(\theta_{A} / \theta_{B}\right) g\left(\theta_{A}, \theta_{B}\right) d \theta_{A} d \theta_{B}
\end{aligned}
$$

Now let $\alpha_{i j}(k)$ be the fraction of the after-tax profits of the firms in region $i$ that accrues to the residents of region $j$ :

$$
\alpha_{i j}(k) \equiv \frac{\sigma_{i j}(k)}{z_{i}(k)}
$$

The net transfer of profits is then

$$
I=(1-\beta)\left[\alpha_{A B}\left(1-t_{A}\right) Y_{A}-\alpha_{B A}\left(1-t_{B}\right) Y_{B}\right]
$$

An equilibrium under the Hamada tax system is a pair of tax rates $\left(t_{A}, t_{B}\right)$ such that neither region can raise its own revenue by unilaterally altering its own tax. The equilibrium must therefore satisfy the best response functions. These functions are obtained by differentiating each

\footnotetext{
${ }^{6}$ This assumption mirrors French and Poterba's (1991) observation that domestic equity is predominently owned by domestic investors.
} 
region's resources, as defined in (10) and (11), with respect to its own tax rate:

$$
\begin{aligned}
\frac{d R_{A}}{d t_{A}} & =\frac{d Y_{A}}{d t_{A}}-\frac{d I}{d t_{A}}=0 \\
\frac{d R_{B}}{d t_{B}} & =\frac{d Y_{B}}{d t_{B}}+\frac{d I}{d t_{B}}=0 .
\end{aligned}
$$

Here, the full derivatives indicate that the government recognizes the effects of its tax rate on $k$ (and hence on both wages and firm location).

\subsection{The Implications of Firm Heterogeneity}

If capital is homogeneous and the regions operate under the Hamada tax system, the signs of the tax rates are determined by $I$. Specifically, $t_{A}$ is positive and $t_{B}$ is negative when $I$ is positive, and the signs are reversed when $I$ is negative. A similar result applies to an economy of $n$ regions: either every region would set its tax rate at zero, or there would be a mix of positive and negative tax rates and possibly some zero tax rates. ${ }^{7}$ This result is at variance with the observed economy, in which governments appear eager to raise revenue through profit taxes, even if their eagerness is restrained by their fear of losing firms to other jurisdictions. By contrast, an economy in which there is firm heterogeneity can easily be an economy in which every tax rate is positive.

The economy is symmetric - every region has the same resources and the same opportunities - if the following conditions are satisfied:

$$
\begin{gathered}
H_{A}=H_{B} \\
g\left(\theta^{\prime}, \theta^{\prime \prime}\right)=g\left(\theta^{\prime \prime}, \theta^{\prime}\right) \quad \text { for all }\left(\theta^{\prime}, \theta^{\prime \prime}\right) \in S \\
s_{A}(q)=s_{B}(1 / q) \quad \text { for all } q>0
\end{gathered}
$$

The first two conditions state that the regions are not intrinsically different: they have the same labour supplies and the same opportunities for production. The third condition states that each region's ownership of the firms varies with the firms' characteristics in the same way. ${ }^{8}$ The

\footnotetext{
${ }^{7}$ The signs of the tax rates are determined by the regions' attempts to manipulate the terms on which capital is imported or exported. Regions that are net importers of capital attempt to reduce capital's after-tax return by taxing capital, while those that are net exporters attempt to raise capital's after-tax return by subsidizing it. A region who is in a zero net importing position sets a zero tax rate. Consequently, there is a mixture of positive and negative tax rates whenever there are net capital movements between at least two regions. If the regions are identical, however, there are no net capital movements and every region sets its tax equal to zero.

${ }^{8}$ For example, if region $A$ owns $60 \%$ of a firm that is twice as productive in $A$ as in $B(q=2)$, region $B$ owns $60 \%$ of the firms that are twice as productive in $B$ as in $A(q=1 / 2)$.
} 
equilibrium tax rates in a symmetric economy can be explicitly calculated:

Result 1: In a symmetric equilibrium incorporating the Hamada tax system, both regions set the tax rate $t^{*}$, where

$$
t^{*}=\frac{\alpha_{B A}(1)}{\phi_{B}(1)+\alpha_{B A}(1)}
$$

and

$$
\phi_{B}(1) \equiv \frac{z_{B}^{\prime}(1)}{z_{B}(1)}>0
$$

Every firm that is not indifferent between the two regions is earning rents, and each government generally appropriates a portion of the rents that are generated within its jurisdiction. Note that it does not wish to collect a share of the rents that would otherwise accrue to domestic residents - it could collect as much of these rents as it wanted through the lump-sum tax - but it does wish to collect a share of the rents that would otherwise accrue to foreigners. Since the government is not permitted to discriminate between foreign and domestic profits, it levies a positive tax on all profits. The level of taxation depends upon the extent of the rents and the degree of foreign ownership.

Consider first the impact of ownership structure. Let $s_{A}^{1}$ and $s_{A}^{2}$ be two structures such that

$$
\begin{array}{ll}
s_{A}^{1}(q) \leq s_{A}^{2}(q) & \text { for all } q<1 \\
s_{A}^{1}(q) \geq s_{A}^{2}(q) & \text { for all } q>1
\end{array}
$$

Then $s_{A}^{1}$ exhibits greater home ownership bias than $s_{A}^{2}$ because the ownership of the firms is concentrated in the regions in which they are most productive. Inspection of (12) and (14) shows that $\alpha_{A A}(1)$ is higher under $s_{A}^{1}$ than under $s_{A}^{2}$, and that $\alpha_{A B}(1)$ is lower. By (17), the equilibrium tax rate falls as the home ownership bias increases. Again, the government's intent is to tax profits that would otherwise accrue to foreigners; the smaller the value of these profits, the smaller is the incentive to tax and the lower is the equilibrium tax rate.

The extent of the rents depends upon the distribution of the productivity factors. By assumption this distribution is symmetric about the $45^{\circ}$ line in the $\left(\theta_{A}, \theta_{B}\right)$ plane. The firms' ability to earn rents is reduced by squeezing this distribution toward the $45^{\circ}$ line. In the limit, the firms become virtually identical, so that all of the firms want to be in $B$ when $k$ is slightly above 1 and all of the firms want to be in $A$ when $k$ is 
slightly below 1 . This behaviour causes $z_{B}^{\prime}(1)$ and $\phi_{B}(1)$ to approach infinity, and $t^{*}$ to approach zero, as the rents are driven to zero.

The tax rate is positive when rents are positive and approaches zero as rents approach zero; but to say more about the relationship between rents and the tax rate, it is necessary to specify exactly the manner in which rents are reduced. One method of shrinking rents is considered here; and while one could imagine other ways, it is not evident that they would have different implications for the model.

Def init ion: Let $S_{n-1}$ be the set of pairs of productivity factors $\left(\theta_{A, n-1}, \theta_{B, n-1}\right)$ for which the density $g_{n-1}\left(\theta_{A, n-1}, \theta_{B, n-1}\right)$ is positive. Define the productivity factors

$$
\theta_{i n} \equiv \lambda \theta_{i, n-1}+(1-\lambda)^{\mu^{\mu}}{\frac{\theta_{A, n-1}+\theta_{B, n-1}}{2}}^{\text {ๆ }} \quad i=A, B
$$

where $\lambda$ is a constant lying between 0 and 1 . Then a compression transforms the original distribution into a new distribution with these properties:

1. $\left(\theta_{A n}, \theta_{B n}\right)$ is contained in $S_{n}$ if and only if $\left(\theta_{A, n-1}, \theta_{B, n-1}\right)$ is contained in $S_{n-1}$.

2. Let $P_{n}$ and $P_{n-1}$ be subsets of $S_{n}$ and $S_{n-1}$, respectively, such that $\left(\theta_{A n}, \theta_{B n}\right)$ is contained in $P_{n}$ if and only if $\left(\theta_{A, n-1}, \theta_{B, n-1}\right)$ is contained in $P_{n-1}$. Then

$$
\mathrm{Z}_{P_{n-1}} g_{n-1}\left(\theta_{A, n-1}, \theta_{B, n-1}\right)={ }_{P_{n}}^{\text {Z }} g_{n}\left(\theta_{A n}, \theta_{B n}\right)
$$

A compression replaces each point in $S_{n-1}$ with a new point that is closer to the $45^{\circ}$ line, so that the set $S_{n}$ is squeezed more tightly about the $45^{\circ}$ line than is $S_{n-1} \cdot{ }^{9}$ Since the new set is smaller than the old set, the density function must be "reweighted" so that mass is not lost.

A compression of the distribution is one way of reducing the economy's rents, and this particular way of reducing rents always results in a lower tax rate.

Result 2: In a symmetric equilibrium incorporating the Hamada tax system, each compression of the distribution reduces $t^{*}$. Furthermore, $t^{*}$ approaches zero as the number of compressions approaches infinity.

\footnotetext{
${ }^{9}$ Starting from some initial set $S_{0}$ and repeatedly applying compressions generates the sets $S_{n}(n=1,2, \ldots)$. These sets converge to the set consisting of the segment of the $45^{\circ}$ line contained in $S_{0}$.
} 
In a symmetric economy, both regions set the same tax rate, and that rate is always positive. Deviations from symmetry will cause the two regions to set different tax rates; but the equilibrium tax rates vary continuously with the parameters of the model, so both tax rates will continue to be positive if the regions are not too dissimilar.

\subsection{The Welfare Effects of a Common Tax Rate}

The regions will generally tax profits at different rates if they differ in their endowments. The disparity in the profit taxes causes firms to be misallocated. If capital is homogeneous the regions can make themselves better off by adopting a common tax rate, but that tax rate must be zero. The regions that subsidize capital must cease to subsidize it, and the regions that tax capital must cease to tax it. The resulting reallocation of capital makes everyone better off. While this result is technically interesting, it is does not hold much promise for governments that hope to meet some of their revenue needs through a tax on corporate profits.

The welfare implications of a common tax rate are more interesting in an economy in which firms are heterogeneous and rents can be earned. There is a range of tax rates that are Pareto improving:

R esult 3: Let $t_{A}^{*}$ and $t_{B}^{*}$ be the tax rates set by the regions in an equilibrium incorporating the Hamada tax system, and assume that these rates are not equal. Then there exist two distinct tax rates $\boldsymbol{D}_{A}$ and $\boldsymbol{D}_{B}$, lying between $t_{A}^{*}$ and $t_{B}^{*}$, such that any harmonized tax rate between $b_{A}$ and $b_{B}$ is Pareto improving.

A switch from unequal tax rates to equal tax rates eliminates the misallocation of firms and raises total output. The increase in output implies that a Pareto improvement is possible, but whether a Pareto improvement actually occurs depends upon the common tax rate, since this rate allocates the output between the two regions. A tax rate that is too low or too high will increase one region's resources by more than the increase in total output, so that the other region's resources must decline. Any less extreme tax rate will split the additional output between the two regions, raising each region's welfare. The tax rates $b_{A}$ and $b_{B}$ allocate all of the extra output to just one region; the intermediate tax rates split it between the regions.

Both equilibrium tax rates are positive if the regions are not too dissimilar, and the range of Pareto-improving tax rates lies entirely between the equilibrium tax rates, so it is quite possible for every Paretoimproving tax rate to be positive. 


\section{Tax Competition under the Wilson Tax System}

Each tax has a separate role under the Hamada tax system: the profits tax determines the region's resources, and the lump-sum tax determines the division of these resources between competing uses. The Wilson tax system consists of just one tax, the profits tax, that simultaneously determines the region's resources and allocates them to competing uses. All of the revenue collected from the profits tax is allocated to the provision of the publicly provided good. Since profits are equal to the fraction $1-\beta$ of all output,

$$
g_{i}=\frac{t_{i}(1-\beta) Y_{i}}{H_{i}}
$$

The remainder of the region's resources are allocated to the private good:

$$
c_{i}=\frac{R_{i}-t_{i}(1-\beta) Y_{i}}{H_{i}}
$$

where $R_{i}$ and $Y_{i}$ are as previously defined. In the tax competition game with Wilson tax system, the objective of the government of region $i$ will set its tax rate to maximize $U_{i}$ subject to (18) and (19). The first-order condition for this maximization problem is

$$
\left(M R S_{i}-1\right)^{\mu}(1-\beta) Y_{i}+t_{i}(1-\beta){\frac{d Y_{i}}{d t_{i}}}^{\text {व }}+\frac{d R_{i}}{d t_{i}}=0
$$

Here, $M R S_{i}$ is region $i$ 's marginal rate of substitution between the private and publicly provided goods; specifically, it is the ratio of the marginal utility of the publicly provided good to the marginal utility of the private good. An equilibrium is a pair of tax rates, one for each region, such that neither region can increase its own welfare by unilaterally altering its own tax rate. That is, it is a pair of tax rates such that (20) is satisfied for each region.

Assume that:

A1. The economy is symmetric.

A2. The utility function in (9) is homothetic.

A3. $M R S_{i}(i=A, B)$ would be smaller than 1 if all of the profits earned in region $i$ were allocated to the provision of the publicly provided good.

The requirements for symmetry are the same as under the Hamada tax system, except that the regions are now required to have the same utility function. The second assumption implies that region $i$ 's marginal rate 
of substitution depends only upon the ratio $c_{i} / g_{i}$. Since $R_{i}$ is equal to $Y_{i}$ under symmetry,

$$
\frac{c_{i}}{g_{i}}=\frac{1}{(1-\beta) t_{i}}-1
$$

An important consequence of $\mathrm{A} 2$ is that changes in the distribution of the productivity factors have no direct impact on the marginal rate of substitution.

Since the marginal rate of transformation betwen the publicly provided good and the private good is 1 , optimal provision of the publicly provided good is characterized by the condition

$$
M R S_{i}=1 \quad i=A, B
$$

This good is overprovided in region $i$ if $M R S_{i}$ is driven below 1 , and it is underprovided if $M R S_{i}$ is held above 1. Assumption A3 states that preferences for the publicly provided good are not so strong as to make overprovision impossible.

Overprovision of the publicly provided good does not occur, even if it is feasible, when capital is homogeneous. However, tax competition can lead to overprovision when firms are heterogeneous.

Result 4: Assume A1-A3. Then overprovision and underprovision are both possible in an equilibrium incorporating the Wilson tax system.

The government's target is again rents, and the greater these rents, the higher the tax rate will be. However, the degree of foreign ownership also matters. The cost of providing another unit of the publicly provided good to each resident (measured in units of the private good) has two components. If a fraction $\gamma$ of the profits accrue to domestic residents, each resident will pay a tax equal to $\gamma$ units of private good (the remainder of the cost of the publicly provided good will be borne by foreigners). However, the higher tax will induce some firms to leave the region, reducing each resident's income by $x$ dollars. The cost of providing the additional unit of public good to each resident is therefore $\gamma+x$ units of private good. The government extends its provision of the publicly provided good until the marginal rate of substitution is just equal to this cost. This good is underprovided if $\gamma+x$ is greater than 1 and underprovided if it is less than $1 .^{10}$

\footnotetext{
${ }^{10}$ If there is underprovision under the Wilson tax system, the tax rate is greater than $t^{*}$, the tax rate that would be set under the Hamada system, even though there is optimal provision under the latter system. Since the government provides more
} 
High foreign ownership of the domestic firms means that $\gamma$ is small; and high rents make the firms reluctant to relocate, so that $x$ is small. Consequently, high foreign ownership and high rents are associated with high taxes.

R esult 5: Assume A1-A3. In an equilibrium incorporating the Wilson tax system, the tax rates and the quantity of publicly provided good rise as $\alpha_{B A}(1)$ rises. Also, the tax rates and the quantity of publicly provided good fall with each compression of the distribution.

The lowest tax rates are attained when the rents have been squeezed from the economy, and at this point, the publicly provided good is underprovided.

\section{Conclusions}

There are substantial differences between a tax competition model with homogeneous capital and one with heterogeneous firms. Profits are generally taxed at a higher rate in the presence of rents. The rate at which they are taxed depends on the extent of foreign ownership as well as the degree of heterogeneity. As well, some established results must be qualified once the existence of rents has been recognized. Specifically, there can be a range of strictly positive Pareto-improving common tax rates under the Hamada tax system, and overprovision and underprovision of publicly provided goods are both possible under the Wilson tax system. These results contradict the findings of capital tax competition models with homogeneous capital.

goods but takes in less revenue through the profits tax under the Hamada system, it must set a positive lump-sum tax to balance its budget. That is, the circumstances that lead to underprovision under the Wilson tax system lead to a positive lump-sum tax under the Hamada system. Equally, the circumstances that lead to overprovision under the Wilson system give rise to a negative lump-sum tax under the Hamada system. Underprovision arises (under the Wilson system) because the government cannot raise revenue in a lump-sum fashion; overprovision arises because it cannot cede revenue in a lump-sum fashion. 


\section{Appendix}

Proof of Result 1: Expanding (16) gives

$$
\frac{\partial Y_{B}}{\partial k} \frac{\partial k}{\partial T}+{ }^{\mu} \frac{\partial I}{\partial k} \frac{\partial k}{\partial T}{ }^{\text {I }} \frac{\partial T}{\partial t_{B}}+(1-\beta) \alpha_{B A} Y_{B}=0
$$

Under symmetry,

$$
\begin{gathered}
\frac{\partial Y_{B}}{\partial k}=-\frac{\partial Y_{A}}{\partial k}=(1-\beta) Y_{B}(1) \phi_{B}(1) \\
\frac{\partial I}{\partial k}=-(1-t)(1-\beta) Y_{B}(1) \phi_{B}(1)\left[1-2 \beta\left(1-\alpha_{B B}(1)\right)\right] \\
\frac{\partial k}{\partial T}=\frac{1}{1+2 \beta \phi_{B}(1)} \\
\frac{\partial T}{\partial t_{B}}=-\frac{1}{1-t}
\end{gathered}
$$

Substituting these expressions into (16) and simplifying gives the result.

Lemma: Let $g_{0}\left(\theta_{A 0}, \theta_{B 0}\right)$ be an initial density function defined on an initial domain $S_{0}$. Define the function

$$
m\left(\theta_{A 0}, \theta_{B 0}\right) \equiv \frac{\theta_{A 0}+\theta_{B 0}}{2}
$$

After $n$ compressions,

$$
\begin{gathered}
\theta_{\text {in }}=\lambda^{n} \theta_{i 0}+\left(1-\lambda^{n}\right) m \quad i=A, B \\
g_{n}\left(\lambda^{n} \theta_{A 0}+\left(1-\lambda^{n}\right) m, \lambda^{n} \theta_{B 0}+\left(1-\lambda^{n}\right) m\right)={\frac{1}{\lambda^{2 n}}}^{\text {वी }} g_{0}\left(\theta_{A 0}, \theta_{B 0}\right)
\end{gathered}
$$

Proof of Lemma: Result (L1) is obtained by forward recursion. To obtain (L2), consider the following subset of $S_{0}$ :

$$
J_{0} \equiv\left\{\left(\theta_{A 0}, \theta_{B 0}\right) \mid p_{A} \leq \theta_{A 0} \leq q_{A}, p_{B 0} \leq \theta_{B 0} \leq q_{B 0}\right\}
$$

The mass of $J_{0}$ is

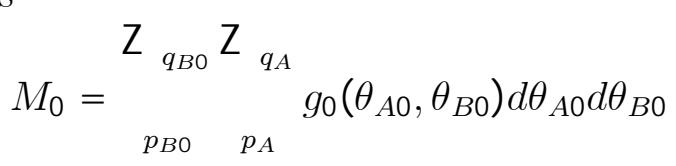

Applying $n$ compressions to $J_{0}$ produces the subset $^{11}$

$$
J_{n} \equiv\left\{\left(\theta_{A n}, \theta_{B n}\right) \mid \theta_{A n} \in X\left(\theta_{B n}\right), p_{B n} \leq \theta_{B n} \leq q_{B n}\right\}
$$

\footnotetext{
${ }^{11}$ This awkward notation is required because the subset produced by compressing a rectangular subset is a flattened and tilted diamond.
} 
where

$$
\begin{gathered}
p_{B n}=\lambda^{n} p_{B 0}+\left(1-\lambda^{n}\right) m \\
q_{B n}=\lambda^{n} q_{B 0}+\left(1-\lambda^{n}\right) m \\
X\left(\theta_{B n}\right)=\left\{\theta_{A n} \mid \theta_{A n}=\lambda^{n} \theta_{A 0}+\left(1-\lambda^{n}\right) m\right. \\
\left.\theta_{B n}=\lambda^{n} \theta_{B 0}+\left(1-\lambda^{n}\right) m \text { for some }\left(\theta_{A 0}, \theta_{B 0}\right) \in J_{0}\right\}
\end{gathered}
$$

The mass of this set is

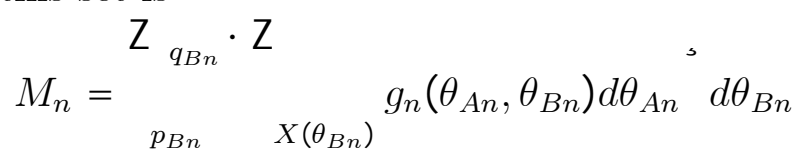

Applying the rule for changing the variable of integration gives

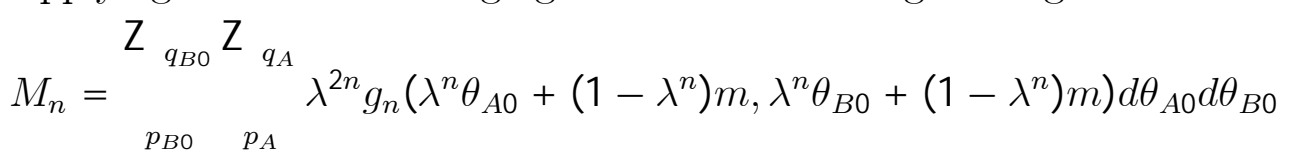

Preservation of the mass requires that $M_{0}$ and $M_{n}$ be equal for any $J_{0}$. This requirement can only be satisfied if the integrands of $M_{0}$ and $M_{n}$ are equal at every $\left(\theta_{A 0}, \theta_{B 0}\right)$.

Proof of Result 2: Let $g_{0}\left(\theta_{A 0}, \theta_{B 0}\right)$ be an initial density function defined on an initial domain $S_{0}$. Let $z_{B n}(k)$ be the aggregated productivity factors of the firms in region $B$, given that the initial distribution has been compressed $n$ times. Then

$$
\begin{aligned}
z_{B n}(1)= & \mathbf{Z}_{\bar{\theta}} \mathbf{Z}_{\theta_{B n}} \theta_{B n} g_{n}\left(\theta_{A n}, \theta_{B n}\right) d \theta_{A n} d \theta_{B n} \\
= & \underline{\mathbf{Z}}_{\bar{\theta}}^{\theta} \mathbf{Z}_{\theta_{B 0}}{ }^{\underline{\theta}} \quad \underline{\theta} \quad\left(\lambda^{n} \theta_{B 0}+\left(1-\lambda^{n}\right) m\right) \lambda^{2 n} \times \\
= & \mathbf{Z}_{\bar{\theta}} \mathbf{Z}_{\theta_{B 0}}\left(\lambda^{n} \theta_{A 0}+\left(1-\lambda^{n}\right) m, \lambda^{n} \theta_{B 0}+\left(1-\lambda^{n}\right) m\right) d \theta_{A 0} d \theta_{B 0} \\
& \underline{\theta} \quad\left(\lambda^{n} \theta_{B 0}+\left(1-\lambda^{n}\right) m\right) g_{0}\left(\theta_{A 0}, \theta_{B 0}\right) d \theta_{A 0} d \theta_{B 0} \\
= & \lambda^{n} z_{B 0}(1)+\left(1-\lambda^{n}\right) \quad \mathbf{Z}_{\bar{\theta}} \mathbf{Z}_{\theta_{B 0}} \quad \underline{\theta} \quad m\left(\theta_{A 0}, \theta_{B 0}\right) g_{0}\left(\theta_{A 0}, \theta_{B 0}\right) d \theta_{A 0} d \theta_{B 0}
\end{aligned}
$$

The second line is obtained by changing the variables of integration, and the third line applies (L2). Since $z_{B n}(1)$ is a weighted average of two values, and each compression increases the weighting of the smaller value, $z_{B n}(1)$ is reduced by each compression. Note, however, that it has 
a positive lower bound. Similarly,

$$
\begin{aligned}
& \mathrm{Z}_{\bar{\theta}} \\
& z_{B n}^{\prime}(1)=\left(\theta_{B n}\right)^{2} g_{n}\left(\theta_{B n}, \theta_{B n}\right) d \theta_{B n} \\
& \frac{\theta}{Z}_{\bar{\theta}} \\
& ={ }_{\underline{\theta}}\left(\lambda^{n} \theta_{B 0}+\left(1-\lambda^{n}\right) m\right)^{2} \lambda^{n} \times \\
& \mathbf{Z}_{\bar{\theta}} \quad g_{n}\left(\lambda^{n} \theta_{B 0}+\left(1-\lambda^{n}\right) m, \lambda^{n} \theta_{B 0}+\left(1-\lambda^{n}\right) m\right) d \theta_{B 0} \\
& ={ }_{\theta}\left(\lambda^{n} \theta_{B 0}+\left(1-\lambda^{n}\right) m\right)^{2} \frac{1}{\lambda^{n}} g_{0}\left(\theta_{B 0}, \theta_{B 0}\right) d \theta_{B 0} \\
& ={\stackrel{\theta}{Z_{\bar{\theta}}}}_{\left(\theta_{B 0}\right)^{2}}^{\mu} \frac{1}{\lambda^{n}} g_{0}\left(\theta_{B 0}, \theta_{B 0}\right) d \theta_{B 0} \\
& ={\frac{1}{\lambda^{n}}}_{1}^{\theta} z_{B 0}^{\prime}(1)
\end{aligned}
$$

The second and third lines are again change of variables and an application of (L2). Each compression raises the value of $z_{B n}^{\prime}(1)$, and

$$
\lim _{n \rightarrow \infty} z_{B n}^{\prime}(1)=\infty
$$

It follows that $\phi_{B}(1)$ increases with each compression, and that it becomes infinitely large as the number of compressions grows.

Proof of Result 3: Any common tax rate maximizes total output. Since

$$
R_{A}+R_{B}=Y_{A}+Y_{B}
$$

a switch from differing tax rates to a common tax rate creates the potential for a Pareto improvement. This potential will be realized if each region's resources are no smaller after harmonization, and at least one region's resources greater, than before harmonization. The common tax rate determines the division of the output by determining the size of the net profit transfer $I$. If the common tax rate is set at $t_{A}^{*}$, region $B$ is no longer making a best response to region $A$ 's tax rate, and hence its resources fall. Region $A$, by contrast, is better off: it is getting all of the increase in output, and some of the output that previously went to region $B$. Likewise, region $A$ is worse off and region $B$ is better off if the common tax rate is $t_{B}^{*}$. To find the range of Pareto-improving tax rates, set the common tax at $t_{A}^{*}$ and adjust it slowly in the direction of $t_{B}^{*}$. The adjustment in the common tax rate raises region $B$ 's share of output and reduces region $A$ 's share. The tax rate $\boldsymbol{P}_{A}$ is the rate at which region $B$ is just as well off as it was before harmonization. Setting the tax rate at $t_{B}^{*}$ and adjusting it in the direction of $t_{A}^{*}$ yields the location of $\boldsymbol{b}_{B}$, the tax 
rate at which region $A$ is just as well off as it was before harmonization. These two rates give all of the additional output to just one region; at any intermediate rate, the increase in output is split between the two regions.

Proof of Result 4: Under symmetry,

$$
\begin{gathered}
\frac{d R_{A}}{d t_{A}}={ }^{\mu} \frac{t}{1-t}-{\frac{\alpha_{B A}(1)}{\phi_{B}(1)}}^{\text {ๆ }} \frac{\partial Y_{A}}{\partial k} \frac{\partial k}{\partial T} \\
\frac{\partial Y_{A}}{\partial k} \frac{\partial k}{\partial T}=-(1-\beta) Y_{A}(1) \phi_{B}(1) \frac{1}{1+2 \beta \phi_{B}(1)}<0
\end{gathered}
$$

Substituting these expressions into (20) and rearranging gives

$$
1-M R S=\frac{\frac{\alpha_{B A}}{\phi_{B}}-\frac{t}{1-t}}{\frac{1}{\phi_{B}}+2 \beta-(1-\beta) \frac{t}{1-t}} \text { 幽 }
$$

The equilibrium tax rate in a symmetric economy is the value of $t$ that satisfies this equation. The accompanying figure shows plots of the leftand right-hand sides of this equation.

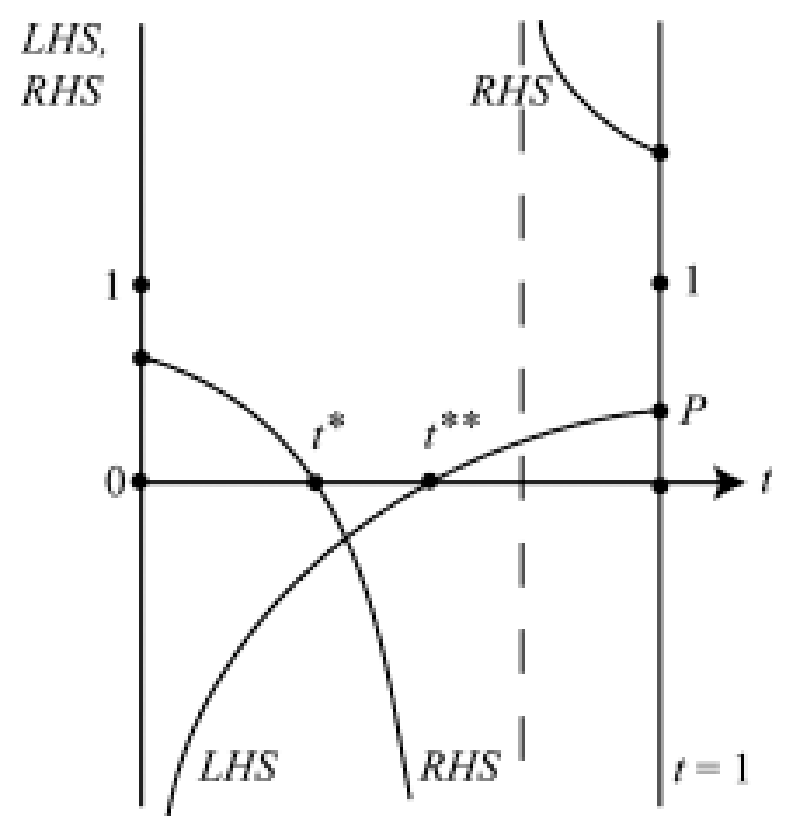

By (21), the left-hand side is an increasing function of $t$. (An increase in $t$ shifts some of the region's resources from the private good to the publicly provided good, reducing $M R S$.) By assumption A3, the point $P$ 
lies above the horizontal axis. The tax rate that would result in optimal provision of the publicly provided good is $t^{* *}$. There is overprovision if the equilibrium rate is greater than $t^{* *}$ and there is underprovision if the equilibrium rate is less than $t^{* *}$.

Now consider the right-hand side, and assume for the moment that $\alpha_{B A}$ is positive. When $t$ is equal to zero, the numerator and the denominator are both positive. At $t^{*}$, as defined in (17), the numerator switches signs. The denominator switches signs at

$$
e=\frac{1+2 \beta \phi_{B}}{1+(1+\beta) \phi_{B}}
$$

causing a discontinuity. The value of the right-hand approaches $1 /(1-\beta)$ as $t$ approaches 1 . The right-hand side decreases as $t$ rises on both sides of the discontinuity.

The tax rate at which the two curves in the figure intersect is the equilibrium tax rate. This rate will be less than $t^{* *}$, and there will be underprovision, if $t^{*}$ is less than $t^{* *}$. It will be greater than $t^{* *}$, and there will be overprovision, if $t^{*}$ is greater than $t^{* *}$. Since $t^{* *}$ is almost entirely determined by preferences, the relative sizes of $t^{*}$ and $t^{* *}$ cannot be determined. Consequently, both underprovision and overprovision are possible.

If $\alpha_{B A}$ is equal to $0, t^{*}$ is also equal to zero and there will necessarily be underprovision.

Proof of Result 5: These results are an extension of the previous proof. The left-hand side of the equation determining the equilibrium tax rate is independent of both $\alpha_{B A}$ and $\phi_{B}$, but both of these factors affect the right-hand side. Inspection shows immediately that an increase in $\alpha_{B A}$ increases the value of the right-hand side at every $t$, causing the equilibrium tax rate to rise. Also, differentiation shows that an increase in $\phi_{B}$ decreases the value of the right-hand side at every $t$, causing the equilibrium tax rate to fall. (The derivative is signed by observing that, to the left of the discontinuity, the value of the right-hand side is always less than $\alpha_{B A}$.) As shown in the proof of result 2, a compression increases $\phi_{B}$, so a compression of the distribution causes the equilibrium tax rate to fall. 


\section{References}

Boadway, R., K. Cuff, and N. Marceau, 2004, 'Agglomeration Effects and the Competition for Firms', International Tax and Public Finance 11, 623-43.

Burbidge, J., J. DePater, G. M yer s, and A. Sengupta, 1997, 'A Coalition Formation Approach to Equilibrium Federations and Trading Blocs', American E conomic Review 87, 940-956.

Dever eux, M., R. Grif $f$ it h, and A . K I emm, 2002, 'Corporate Income Tax Reforms and International Tax Competition', E conomic P olicy 17, 450-495.

French, K. and J. P ot er ba, 1991, 'Investor Diversification and International Equity Markets', American Economic Review 81, 222-226.

H a mada, K ., 1966, 'Strategic Aspects of Taxation on Foreign Investment Income', Quarterly J ournal of E conomics 80, 361-375.

Huizinga, H. and S. B o Niel sen, 1997, 'Capital Income and Profit Taxation with Foreign Ownership of Firms', J ournal of International E conomics 42, 149-165.

Lee, K ., 2003, 'Factor Ownership and Governmental Strategic Interaction', J ournal of Public Economic Theory 5, 345-361.

M ansoorian, A . and G. M yer s, 1993, 'Attachment to Home and Efficient Purchases of Population in a Fiscal Externality Economy', J ournal of Public Economics 52, 117-132.

Peralta, S. and T. van Y per sele, 2002, 'Coordination of Capital Taxation Among Asymmetric Countries', CORE Discussion Paper 32.

W il so $n, J$., 1999, 'Theories of Tax Competition', National Tax J ournal 52, 269-304. 